\title{
Effect of level of input of different proportions of volatile fatty acids on energy utilization in growing ruminants
}

\author{
BY E. R. ØRSKOV AND N. A. MACLEOD \\ Rowett Research Institute, Bucksburn, Aberdeen AB2 $9 S B$
}

(Received 26 May 1992 - Accepted 9 January 1993)

\begin{abstract}
Four steers were maintained wholly by intragastric infusion of volatile fatty acids (VFA) and protein, together with a mineral-vitamin supplement. The infusion was given at three levels of energy, namely 450,675 and $900 \mathrm{~kJ} / \mathrm{kg}$ live weight ${ }^{.75}$, calculated to supply energy at $1.0,1.5$ or 2.0 times that required for maintenance. The VFA provided 0.837 and the protein 0.163 of the energy infused. The molar proportions of individual VFA were varied so that the infusate contained $0.36-0.91$ of acetic acid, $0.56-0.01$ of propionic acid and a constant 0.08 of butyric acid. Heat production was measured in respiration chambers. Urine was analysed for $\mathrm{N}$, urea, $\beta$-hydroxybutyrate and VFA. Blood plasma was analysed for $\beta$-hydroxybutyrate, free fatty acids, insulin and glucose. As the proportion of acetic acid was increased, and propionic acid reduced, there was no change in blood or urine metabolites or in heat production until acetic acid exceeded a proportion of about 0.75. At higher proportions $\beta$ hydroxybutyrate increased in plasma and urine, blood glucose and insulin tended to fall and urinary $\mathbf{N}$ excretion rose. At a proportion of acetic acid of $>0.80$, acetate appeared in the urine and at $>0.86$ heat production declined. The effect of level of infusion on the molar proportion at which plasma and urine metabolites changed was less clear. There was a tendency for the increase in $\beta$-hydroxybutyrate to occur at a slightly lower proportion of acetic acid at the highest level of infusion. It is concluded that differences in heat production that are observed between diets are probably not caused by differences in rumen VFA proportions. The reaction to a highly elevated proportion of acetic acid is to excrete $\beta$-hydroxybutyrate and acetate in the urine and so decrease rather than increase heat production. Regardless of level of infusion a metabolic crisis occurred when the proportion of acetic acid was above the levels found in the rumen content of normally-fed animals.
\end{abstract}

Volatile fatty acids: Energy utilization: Steers

Barcroft et al. (1944) first showed that volatile fatty acids (VFA) produced by fermentation in the rumen constituted the main source of energy for ruminant tissues. Controversy has existed ever since as to whether there were differences in the utilization of VFA which perhaps could account for observed differences in the utilization of metabolizable energy (ME), with particular reference to the differences observed between roughages and concentrate diets. When it was established that the proportion of acetic acid in the rumen was generally greater with roughage than with concentrate McClymont (1952) suggested that inefficient utilization of acetic acid was probably the reason for the differences in $\mathrm{ME}$ utilization. Armstrong \& Blaxter (1957) reported some results indicating the possibility that acetic acid was indeed utilized less efficiently than propionic acid. This observation led to many attempts by nutritionists to find methods of increasing the proportion of propionic acid and decreasing the proportion of acetic acid in the rumen fermentation. However, as summarized by Ørskov \& MacLeod (1990), there were problems in the interpretation of work based on supplementing diets with VFA or with salts of VFA in that only about $0 \cdot 15$ of ME could be substituted before problems of inappetence occurred (Ørskov \& Allen, 1966). Supplementation with VFA also assumed that there was no effect on the digestion 
of the basal diet. Furthermore, adding $0 \cdot 15$ of $\mathrm{ME}$ as acetic acid to a diet already producing a high proportion of acetic acid would result in abnormal proportions of acetic acid in the rumen. These aspects have been discussed in some detail by Ørskov \& Ryle (1990) and Ørskov \& MacLeod (1990).

The technique of intragastric nutrition (Ørskov et al. 1979b) removed many of the problems and in earlier studies with sheep covering a wide range in VFA we found no differences in utilization of different VFA (Ørskov et al. 1979a). In recent work we reported (Ørskov et al. 1991) VFA infusions in which the molar proportion of acetic acid was varied from $0 \cdot 16$ to 0.91 with the molar proportion of propionic acid varying reciprocally. There were no differences in animal metabolism and energy utilization when the proportions of VFA were varied within their normal rumen range. However, when the acetic acid exceeded about 0.80 of the VFA, plasma $\beta$-hydroxybutyrate was elevated, $N$ excretion increased and at still higher proportions this was accompanied by the appearance of acetic acid in the urine and a decrease in heat production. It seemed that when the proportion of acetic acid was well above normal values it was inefficiently metabolized due to glucose deficiency. It appears that the animals did not elevate heat production but excreted acetate in the urine. In this previous work only one level of infusion was given, namely 1.5 times the estimated maintenance requirement. In the present work, therefore, heat production and metabolism were examined using a wide range of VFA proportions and at three levels of infusion, namely $1.0,1.5$ and 2.0 times the estimated maintenance energy requirement. The protein:energy ratio was deliberately held low to ensure that little in the way of glucose precursors could be derived from that source.

\section{MATERIALS AND METHODS \\ Animals}

Two Friesian steers of mean live weight (W) $250 \mathrm{~kg}$ and two Charollais $\times$ Friesian steers of mean W $290 \mathrm{~kg}$ were used as consecutive pairs in the present study. They were, on average, 9 months old when surgically prepared with rumen cannulas and abomasal catheters. The animals were housed in individual pens and offered a mixed hay and concentrate diet before, and for approximately 5 weeks after surgery. They were then transferred to two open-circuit respiration chambers where normal diets were discontinued and nutrients supplied by intragastric infusions (Ørskov et al. 1979 b; MacLeod et al. 1982). Each pair remained in the chambers on infusion for the whole of the trial period.

\section{Treatments and design}

As only two respiration chambers were available the experiment was conducted with two consecutive pairs of steers. The aim was to study the interaction between different molar proportions of the VFA mixture infused and the level of nutrient intake. The three energy levels supplied were 450,675 and $900 \mathrm{KJ} / \mathrm{kg} \mathrm{W}^{0.75}, 0 \cdot 837$ arising from VFA and $0 \cdot 163$ from protein (casein) (Ørskov et al. 1991). Allocation to these nutrient levels is shown in Table 1. Within each energy level the initial molar proportion of acetic acid in the VFA mixture infused was $36 \mathrm{~mol} / 100 \mathrm{~mol}$ increasing to a maximum of $91 \mathrm{~mol} / 100 \mathrm{~mol}$, giving the eight subtreatments as shown in Table 2.

The actual proportions of energy contributed by acetic, propionic and butyric acids and of protein for the extreme treatments are given in Table 3. The proportionate energy contribution from each of the nutrients infused, at the lowest and highest levels of acetic acid in the VFA mixture, is shown in Table 3.

Each subtreatment in the present experiment was of 2-3 d duration, except that for the energy level of $900 \mathrm{KJ} / \mathrm{kg} \mathrm{W}^{0 \cdot 75}$ at $91 \mathrm{~mol} / 100 \mathrm{~mol} \mathrm{VFA}$. In this subperiod the animals 
Table 1. Sequence of level of energy infusion $\left(\mathrm{kJ} / \mathrm{kg}\right.$ live weight $\left.{ }^{0.75}\right)$

\begin{tabular}{cccc}
\hline Period $\ldots$ & 1 & 2 & 3 \\
\hline Steer no. & & & \\
1 & 450 & 675 & 900 \\
2 & 675 & 450 & 900 \\
3 & 900 & 450 & 675 \\
4 & 450 & 900 & 675 \\
\hline
\end{tabular}

Table 2. Sequence in which different volatile fatty acid (VFA) mixtures (mol/100 mol total $V F A)$ were given in each energy level treatment

\begin{tabular}{lrrrrrrrrr}
\hline Subtreatment ... & 1 & 2 & 3 & 4 & 5 & 6 & 7 & 8 \\
\hline Acetic acid & 36 & 46 & 56 & 66 & 76 & 81 & 86 & 91 \\
Propionic acid & 56 & 46 & 36 & 26 & 16 & 11 & 6 & 1 \\
Butyric acid & 8 & 8 & 8 & 8 & 8 & 8 & 8 & 8 \\
\hline
\end{tabular}

Table 3. Proportions of energy supplied as acetic, propionic and butyric acids and of proteins of the mixtures highest and lowest in acetic acid proportions $(\mathrm{kJ} / 100 \mathrm{~kJ}$ in infusate)

\begin{tabular}{lcc}
\hline$=$ & \\
& Acetic acid \\
$($ mol/100 mol $) \ldots$ & 36 & 91 \\
\hline Acetic acid & 0.20 & 0.68 \\
Propionic acid & 0.53 & 0.01 \\
Butyric acid & 0.11 & 0.15 \\
& 0.16 & 0.16 \\
\hline
\end{tabular}

were so severely affected that observations were obtained from one animal within each pair for $1 \mathrm{~d}$ only, and from the other animal for $2 \mathrm{~d}$. In the results the values given are mean values based on all observations in each subperiod. Hovell et al. (1983) showed that responses to changes in energy and protein levels were rapid and that the values even on the first day of change were typical.

\section{Management}

Two respiration chambers were used to house the steers for the duration of the experiment. They contained conventional concrete-walled stalls with rubber mat flooring and an inset tubular metal grid. Urine passed through the grid into a fibreglass tray and then directly into a plastic container. Faeces were collected onto a separate fibreglass tray but because no solid food was eaten the amounts excreted were small and on some days none was excreted. Faeces were totalled, therefore, over each of the energy level periods. The chambers were left open during preliminary periods. Over experimental periods they were opened for approximately $1 \mathrm{~h}$ each morning to allow for removal of rumen fluid samples and to administer trace minerals and vitamins into the abomasum by syringe. Venous blood was withdrawn on the last day of each subtreatment. Chamber gas was continuously exhausted. 


\section{Measurements of heat production}

$\mathrm{O}_{2}$ and $\mathrm{CO}_{2}$ concentrations were measured in chamber exhaust air and compared with those of room air. The $\mathrm{O}_{2}$ concentration was measured with a paramagnetic analyser (Servomex OA 184; Sybron Analytics, Crowborough, Sussex) and the concentration of $\mathrm{CO}_{2}$ with an infra red analyser (Model SS100, The Analytical Development Company, Hoddesdon, Hertfordshire). Heat production was then calculated from the changes in both gases (Brouwer, 1965). Chamber and room air were continuously sampled in $2 \mathrm{~h}$ cycles over $24 \mathrm{~h}$ periods. Exhaust air was channelled over alternate $27 \mathrm{~min}$ intervals from each of the chambers through gas analysers and room air sampled for $10 \mathrm{~min}$ in each $2 \mathrm{~h}$ cycle.

\section{Collection and analysis of urine}

Urine was collected over $24 \mathrm{~h}$ periods and acidified to $<\mathrm{pH} 4$ using $\mathrm{H}_{2} \mathrm{SO}_{4}(100 \mathrm{ml} / \mathrm{l})$. It was weighed daily and subsampled for analysis. Total $\mathrm{N}$ was determined by the automated Kjeldahl method of Davidson et al. (1970). The technique of Technicon Instrument Co. based on a modification by Marsh et al. (1965) was used for urea. Total VFA and proportions of individual VFA were determined using gas-liquid chromatography with a flame-ionization detector according to Ottenstein \& Bartley (1971).

\section{Analysis of blood samples}

Two blood samples $(20 \mathrm{ml})$ were withdrawn by venepuncture from a jugular vein into evacuated tubes containing heparin and EDTA on the last day of each subtreatment period, and the tubes were centrifuged for $10 \mathrm{~min}$ at $1200 \mathrm{~g}$ (Centrifuge model Centra-3e; International Equipment, Dunstable, Bedfordshire) and the plasma was stored at $-70^{\circ}$ until analysed. Free fatty acids (FFA) were estimated on the EDTA samples using the WAKO Chemicals GmbH Enzymatic Colorimetric Method (WAKO Chemicals GmbH, Nissanstr. 2, 4040 Meuss 1, Germany). All other determinations were made on the heparinized samples. Glucose was determined by the method of Trinder (1969), insulin by radioimmunoassay (RIA) (Basset \& Thorburn, 1971), urea by the method of Marsh et al. (1965), and $\beta$-hydroxybutyrate by that of Zivin \& Snarr (1973).

\section{Rumen samples}

Samples of rumen fluid, approximately $50 \mathrm{ml}$, were withdrawn twice daily at 09.00 and 17.00 hours through the rumen cannula with a $300 \mathrm{~mm}$ length of vinyl tube attached to a syringe and the $\mathrm{pH}$ and osmolality were determined immediately. As described in more detail previously (Hovell et al. 1987), the aim was to keep rumen $\mathrm{pH}$ between 6.0 and 6.5 and osmolality below $330 \mathrm{mosmol} / 1$, adjusting VFA: buffer solutions infused as required. The total volume of infusates to both rumen and abomasum was approximately $1.0 \mathrm{~kg} / \mathrm{kg}$ $\mathrm{W}^{0.75}$, of which approximately $75 \%$ was directed to the rumen as diluted VFA and buffer solutions and $25 \%$ to the abomasum as soluble casein.

\section{Statistical analysis}

The variation in energy and protein supplies gave obvious changes in most variables. Results are mean values with their standard errors for each measurement. Since the main objective was to see if the molar value for acetic:propionic acid infused at which metabolic problems arose changed with the level of energy supply, an attempt was made to calculate when plasma and urine concentrations deviated from normal by more than $2 \mathrm{SE}$. For each animal and at each infusion level no deviation from normal was evident when the infused acetic acid formed less than about $70 \mathrm{~mol} / 100 \mathrm{~mol}$ total VFA. Above this value an exponential relationship between acetic acid $(\mathrm{mol} / 100 \mathrm{~mol})$ and metabolite concentration 

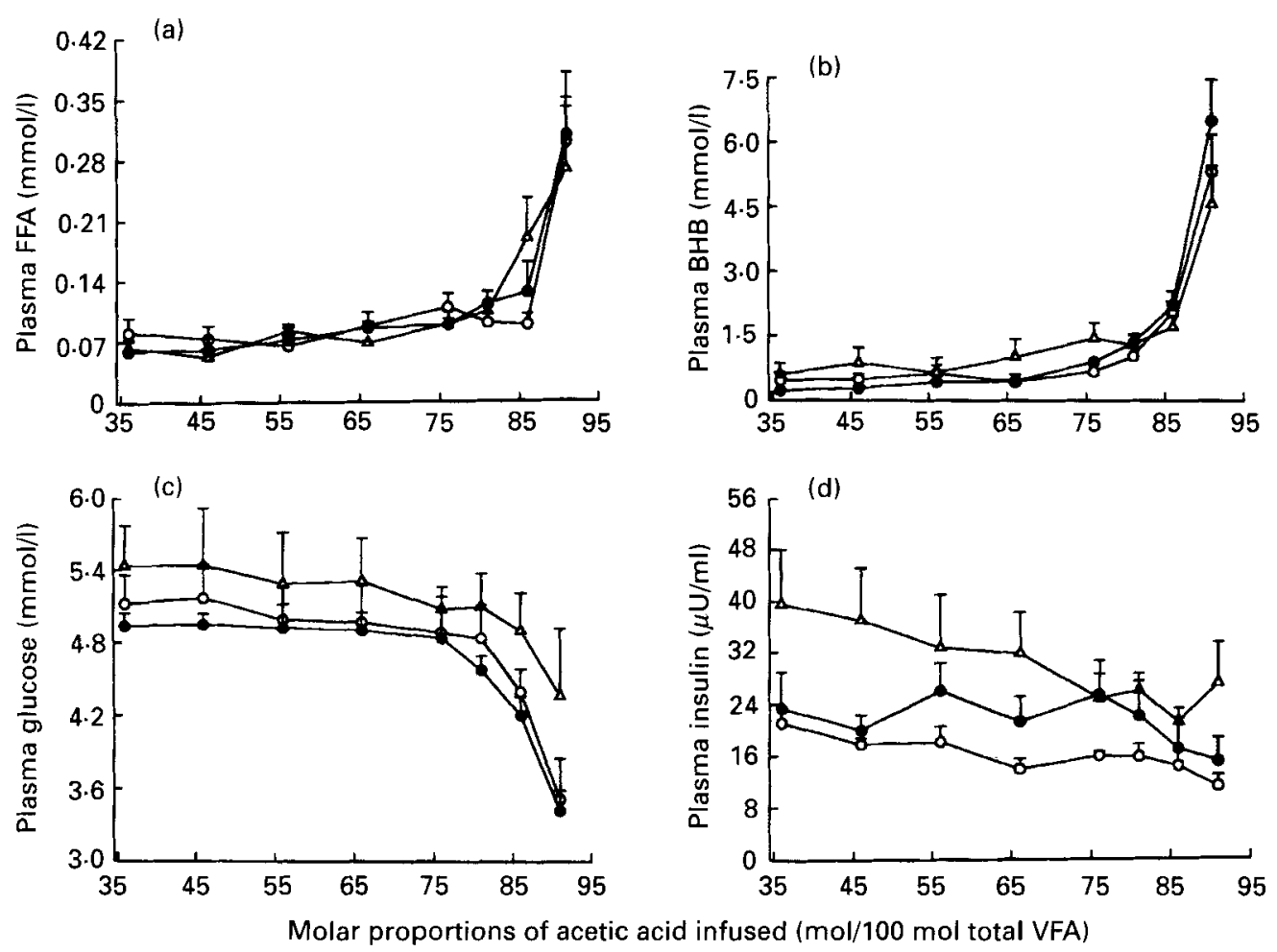

Fig. 1. Effect of infusing different molar proportions of volatile fatty acids (VFA) at a $1.0(O) 1.5(O)$ or $2.0(\triangle)$ times estimated maintenance requirement on (a) plasma free fatty acids (FFA), (b) plasma $\beta$-hydroxybutyrate (BHB), (c) plasma glucose, and (d) plasma insulin in steers. Values are means with their standard errors represented by vertical bars. For details of procedures, see pp. $680-683$.

was assumed. The value for the proportion of acetic acid which corresponded to 2 SD was estimated by the mean value +2 sD or when the mean value +2 sD was cut by the exponential line. For plasma FFA there were response curves for twelve animal-treatment combinations each providing an estimate of the threshold at which the response changed. These twelve estimates were subjected to a two-way analysis of variance to determine whether the treatment affected the mean threshold value. A similar process was adopted for plasma $\beta$ hydroxybutyrate and urinary $\beta$-hydroxybutyrate. In practice fitting linear and exponential curves or two linear curves provided good estimates of the threshold value for most response curves. However, for three of the values for plasma FFA and one value for each of the plasma and urinary $\beta$-hydroxybutyrate the estimates were poor and replaced by missing values in the analysis.

\section{RESULTS \\ Plasma}

There was no significant difference between the three levels of energy infusion in the molar proportions of infused acetic acid at which the plasma $\beta$-hydroxybutyrate was elevated (Fig. 1(a)). The breaking points as defined earlier, occurred at molar proportions of acetic acid of $76.5,76.8$ and 76.9 for the $1.0,1.5$ and 2.0 times energy maintenance inputs respectively. Essentially the same relationship was found for plasma FFA (Fig. 1(b)). Again there was no significant difference between the infusion levels at which the FFA 

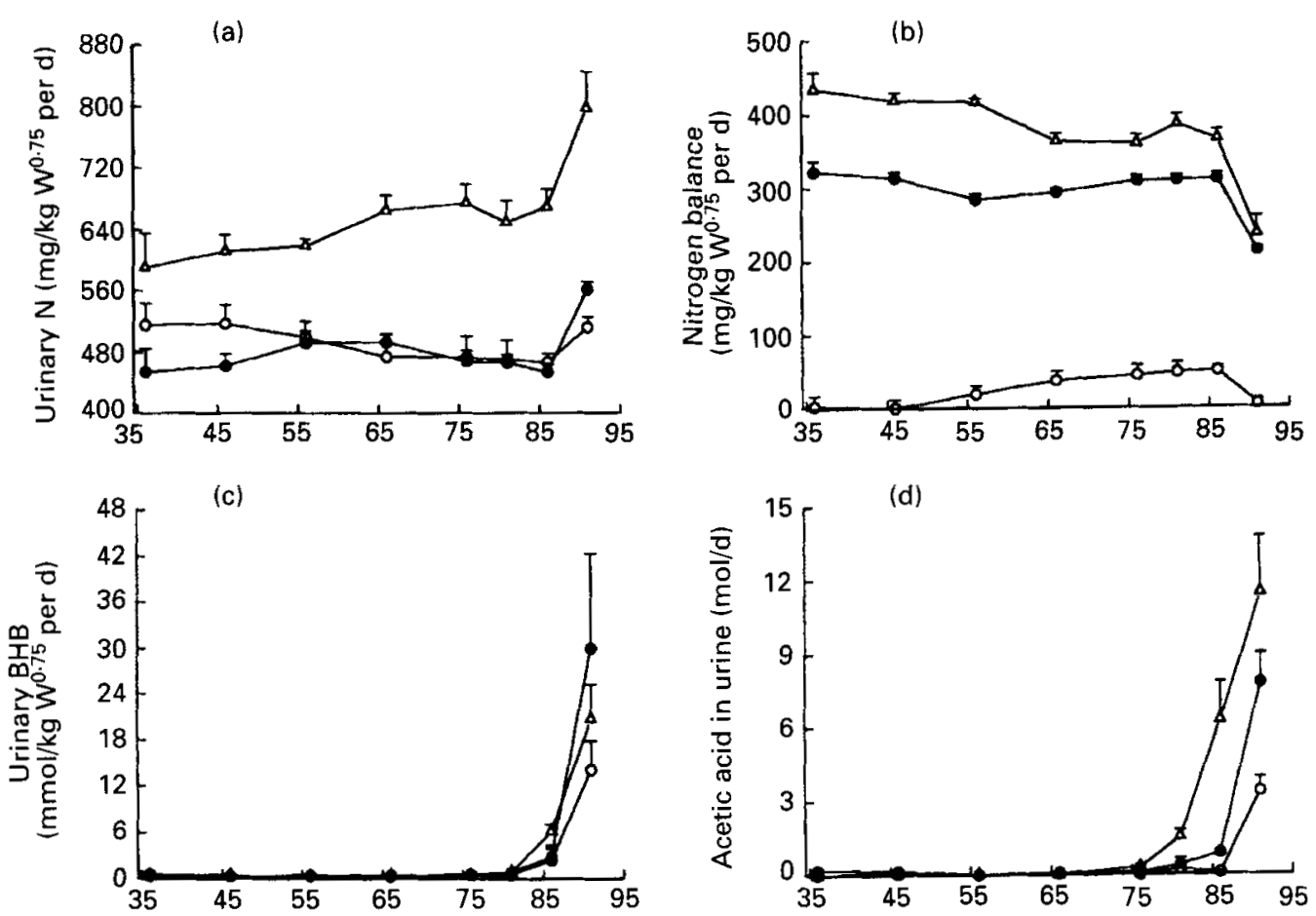

Molar proportions of acetic acid infused (mol/100 mol total VFA)

Fig. 2. Effect of infusing different molar proportions of volatile fatty acids (VFA) at a $1.0(\bigcirc) 1.5(\bigcirc)$ or $2.0(\triangle)$ times estimated maintenance requirement on (a) urinary nitrogen excretion, (b) $\mathrm{N}$ balance, (c) urinary $\beta$ hydroxybutyrate (BHB) and (d) urinary acetic acid in steers. Values are means with their standard errors represented by vertical bars. For details of procedures, see pp. 680-683. W, live weight.

concentration increased, the molar proportion of acetic acid at which the FFA concentration was elevated according to the definition explained being 87.0, 80.6 and $84 \cdot 1$ at $1.0,1.5$ and 2.0 times energy maintenance.

Plasma glucose concentration (Fig. 1(c)) was reduced at about the same molar proportion of infused acetic acid as $\beta$-hydroxybutyrate and FFA was increased. Due to considerable variation it was difficult to define clearly the critical molar proportion of acetic acid. The depression was only significant $(P<0.05)$ at levels of energy infusion at 1.0 and 1.5 times energy maintenance. There was a tendency for a decrease in plasma insulin (Fig. 1 (d)) with increasing proportions of acetic acid but the relationship was not significant.

\section{Urine}

A significant $(P<0.05)$ increase in urinary $\mathrm{N}$ excretion (Fig. 2(a)) occurred at all levels of energy infusion when $91 \mathrm{~mol}$ acetic acid $/ 100 \mathrm{~mol}$ total VFA was infused. It was not possible to define the critical value more precisely. $N$ balance (Fig. 2(b)) showed an almost exactly reciprocal relationship to urinary $\mathrm{N}$ excretion, as is to be expected when urinary $\mathrm{N}$ excretion is the predominant route of $\mathrm{N}$ elimination. The urinary $\beta$-hydroxybutyrate concentration is given in Fig. 2 (c). From the regression equation, it was calculated that the $\beta$-hydroxybutyrate value was 2 SE above normal at acetic acid molar proportions of $82 \cdot 1$, 80.9 and 79.5 and corresponding levels of $1,1.5$ and 2 times energy maintenance respectively. These values did not differ significantly. Such regression equations could not 


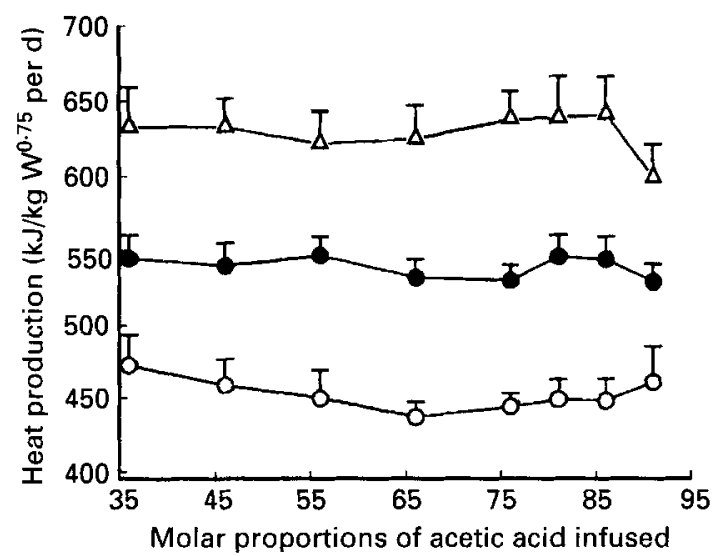

Fig. 3. Effect of infusing different molar proportions of volatile fatty acids (VFA) at a $1.0(O) 1.5(O)$ or $2 \cdot 0(\triangle)$ times estimated maintenance requirement on heat production. The energy contained in the infusates were 450,675 and $900 \mathrm{~kJ} / \mathrm{kg}$ live weight $(\mathrm{W})^{0.75}$ for the $1.0,1.5$ and 2.0 times maintenance respectively in steers. Values are means with their standard errors represented by vertical bars. For details of procedures, see pp. $680-683$.

be described in the case of urinary acetic acid excretion (Fig. 2(b)). However, while at two times energy maintenance excretion became significant $(P<0.05)$ between 81 and $86 \mathrm{~mol}$ acetic acid $/ 100 \mathrm{~mol}$ total VFA), it was only significant for 1.0 and 1.5 times energy maintenance between 86 and $91 \mathrm{~mol} / 100 \mathrm{~mol}$ total VFA.

\section{Whole-body energy balance}

At the highest level of energy infusion heat production was significantly reduced when infused acetic acid reached a molar proportion of $91 \mathrm{~mol} / 100 \mathrm{~mol}$ total VFA, no doubt due to the excretion of unoxidized acetic acid and $\beta$-hydroxybutyrate in the urine (Fig. 3).

\section{DISCUSSION}

Effect of level of energy infusion on heat production from different volatile fatty acids The results do not provide much support for the hypothesis that level of energy infusion affects the point at which increasing proportions of acetic acid in the infusion mixture give rise to metabolic problems including deficiency of glucose precursors. The critical 'breaking point' in ascending proportions of acetic acid was between 76 and $77 \mathrm{~mol} / 100 \mathrm{~mol}$ total VFA for plasma $\beta$-hydroxybutyrate, between 81 and $87 \mathrm{~mol} / 100 \mathrm{~mol}$ total VFA for plasma FFA, and similar values for plasma glucose. Urinary $\beta$-hydroxybutyrate increased between 80 and $82 \mathrm{~mol} / 100 \mathrm{~mol}$ total VFA, and urinary $\mathrm{N}$ and acetic acid increased between the 86 and $91 \mathrm{~mol} / 100 \mathrm{~mol}$ total VFA values. In no case was there a significant difference between these critical values and the level of energy infusion. A significant fall in heat production, at $91 \mathrm{~mol}$ acetic acid/100 mol total VFA was observed only at the twice maintenance level of infusion, but this was probably because the absolute losses of acetic acid and $\beta$ hydroxybutyrate only became significant at this level.

It would appear, therefore, that within the infusion levels adopted here the ratio of glucose precursors in the infusate, i.e. the proportion of propionic acid, was more important than the levels at which it was infused.

It is of interest of course that the metabolic problems occurred only when the molar proportion of acetic acid was considerably higher than is ever produced on practical diets. From the early work of Armstrong \& Blaxter (1957) an increase in heat production may 
have been expected to accompany increasing molar proportions of acetic acid but there was in fact a decrease that was probably due to loss of $\beta$-hydroxybutyrate and of acetic acid excreted in the urine. Thus, ruminants appear not to respond to an excess of acetic acid by increasing heat production or in futile cycling but by excreting excess acetic acid in the urine (for extensive discussion, see also Ørskov \& Ryle, 1991).

\section{Efficiency of utilization of mixtures of volatile fatty acids for energy retention}

In previous work of Ørskov et al. (1991) the efficiency of utilization could not be assessed since there was only one level of infusion of energy. Here, however, this is possible. If the highest proportion of acetic acid $(91 \mathrm{~mol} / 100 \mathrm{~mol}$ total VFA) is ignored the efficiency between levels 1 and 1.5 was 0.613 and between levels 1.5 and 2 was 0.591 . The mean value of 0.60 is almost identical to the mean value observed in the earlier work with sheep (Ørskov et al. 1979a) and from caecal infusion of VFA in pigs (Gadeken et al. 1989).

\section{Effect of volatile fatty acids on glucose metabolism}

As in previous work (Ørskov et al. 1991), when there is an apparent glucose deficiency accompanying high proportions of acetic acid in the VFA absorbed there was also an increased excretion of $\mathrm{N}$ in the urine. This is no doubt due to the fact that glucose precursors arising from protein turnover were being utilized for fatty acid oxidation and synthesis. It is interesting to note that when fatty tissue is being oxidized, as in fasting, there is a consistent $40 \%$ increase in $\mathrm{N}$ excretion (Asplund et al. 1985). When small amounts of glucose or propionic acid were infused the $\beta$-hydroxybutyrate and FFA concentrations returned to normal levels (KuVera et al. 1989). As in previous work, plasma glucose and insulin concentrations were reduced when the proportions of acetic acid exceeded about $81 \mathrm{~mol} / 100 \mathrm{~mol}$ total VFA.

\section{Practical implications}

It must of course be considered that ruminants nourished by intragastric nutrition differ from normal ruminants in so far that no fibre is being propelled through the gut. This has an effect on the thickness of the wall of the small intestine (see Orskov et al. 1979a) while the rumen epithelium papillae length and mitotic index is the same. Animals on intragastric nutrition do not receive rumen microbes unless rumen microbes are infused and, as such, a range of nutrients absorbed in normally-fed ruminants are not absorbed here. Since, however, the VFA are the main source of energy and the range of VFA used here is larger than that which occur in practice, it seems reasonable to suggest that in practice changes in proportions of VFA can only benefit the animals' energy balance if as a result $\mathrm{CH}_{4}$ production is decreased, as can be expected when acetic acid is increased (Ørskov et al. 1968). Within the normal range of proportions of VFA produced from different diets reported in the literature the utilization of absorbed energy or $\mathrm{ME}$ is unlikely to be influenced by the proportions of VFA. Manipulating the type of fermentation so that a very high proportion of propionic acid is produced can create problems in dairy cows as it increases plasma insulin and so depresses milk fat synthesis. The fact that ruminants lack the citrate-cleavage enzyme makes them convert glucose or glucose precursors only slowly to fatty acids (Crabtree et al. 1987).

It appears, therefore, as discussed in a recent review (Ørskov \& MacLeod, 1990), and further evidenced by Ørskov et al. (1991), that differences in utilization of ME between roughages and concentrate can probably not be attributed to differences in the proportions of VFA produced, as advocated by Blaxter (1962), but must have other causes such as differences in physical activity, particularly those associated with the duration of eating and rumination (Ørskov \& Ryle, 1990). 
The authors wish to thank Lynne Giles for advice on statistical procedure and carrying out the statistical analysis.

\section{REFERENCES}

Armstrong, D. G. \& Blaxter, K. L. (1957). The utilization of acetic, propionic and butyric acids by fattening sheep. British Journal of Nutrition 11, 413-425.

Asplund, J. M., Ørskov, E. R., Hovell, F. D. DeB. \& MacLeod, N. A. (1985). The effect of intragastric infusion of glucose, lipids, or acetate on fasting nitrogen excretion and blood metabolites in sheep. British Journal of Nutrition 54, 189-195.

Barcroft, J., McAnally, R. A. \& Phillipson, A. T. (1944). Absorption of acetic, propionic and butyric acids from the alimentary canal. Biochemical Journal 38, III.

Basset, J. M. \& Thorburn, G. D. (1971). The regulation of insulin secretion by the ovine foetus in utero. Journal of Endocrinology 50, 59-74.

Blaxter, K. L. (1962). Energy Metabolism in Ruminants. London: Hutchingson Scientific and Technical.

Brouwer, E. (1965). In Energy Metabolism, p. 441 [K. L. Blaxter, editor]. London: Academic Press.

Crabtree, B., Barr, S. A., Anderson, S. E. \& MacRae, J. C. (1987). Measurement of the rate of substrate cycling between acetate and acetyl-CoA in sheep muscle in vivo: effects of infusion of acetate. Biochemical Journal 243, $821-827$.

Davidson, J., Mathieson, J. \& Boyne, A. W. (1970). The use of automation in determining nitrogen by the Kjeldahl method with final calculations by computer. Analyst 95, 181-193.

Gadeken, D., Breves, G. \& Oslage, H. J. (1989). Efficiency of energy utilization of intracaecally infused volatile fatty acids in pigs. In Proceedings of the 11th Symposium on Energy Metabolism. European Association of Animal Production Publication no. 43, pp. 115-118 [Y. van der Honine and W. H. Close, editors]. Wageningen, The Netherlands: Pudoc.

KuVera, J. C. (1989). Energy and nitrogen metabolism in cattle nourished by intragastric infusion of nutrients. PhD Thesis, Aberdeen University.

Hovell, F. D. DeB., Ørskov, E. R., Kyle, K. J. \& MacLeod, N. A. (1987). Undernutrition in sheep. Nitrogen repletion by $\mathrm{N}$-depleted sheep. British Journal of Nutrition $\mathbf{5 7}, 77-88$.

Hovell, F. D. DeB., Ørskov, E. R., MacLeod, N. A. \& McDonald, I. (1983). The effect of changes in the amount of energy infused as volatile fatty acids on the nitrogen retention and creatinine excretion of lambs nourished by intragastric nutrition. British Journal of Nutrition 50, 331-343.

McClymont, G. L. (1952). Specific dynamic actions of acetic acid and heat increment of feeding in ruminants. Australian Journal of Scientific Research 5, 374.

MacLeod, N. A., Corrigall, W., Stirton, R. A. \& Ørskov, E. R. (1982). Intragastric infus nutrients in cattle. British Journal of Nutrition 47, 547-552.

Marsh, W. H., Fingerhut, B. \& Millar, H. (1965). Automated and manual direct methods for determination of blood urea. Clinical Chemistry 11, 624-627.

Orskov, E. R. \& Allen, D. M. (1966). Utilization of salts of volatile fatty acids by growing sheep. 4. Effects of type of rumen fermentation of the basal diet on the utilization of salts of volatile fatty acids for nitrogen retention and body gains. British Journal of Nutrition $20,519-532$.

Ørskov, E. R., Flatt, W. P. \& Moe, P. W. (1968). A fermentation balance approach to estimate extent of fermentation and efficiency of volatile fatty acid formation in ruminants. Journal of Dairy Science $\mathbf{5 1}$, $1429-1503$.

Ørskov, E. R., Grubb, D. A., Smith, J. S., Webster, A. J. F. \& Corrigall, W. (1979a). Efficiency of utilization of volatile fatty acids for maintenance and energy retention by sheep. British Journal of Nutrition 41, 541-551.

Orskov, E. R., Grubb, D. A., Wenham, W. \& Corrigall, W. (1979b). The sustenance of growing and fattening ruminants by intragastric infusion of volatile fatty acids and protein. British Journal of Nutrition 41, 553-558.

Ørskov, E. R. \& MacLeod, N. A. (1990). Dietary induced thermogenesis and feed evaluation in ruminants. Proceedings of the Nutrition Society 49, 227-237.

Orskov, E. R., MacLeod, N. A. \& Nakashima, Y. (1991). Effect of different volatile fatty acid mixtures on energy metabolism in cattle. Journal of Animal Science 69, 3389-3397.

Ørskov, E. R. \& Ryle, M. (1990). Energy Nutrition in Ruminants. London and New York: Elsevier Applied Science Publishers.

Ottenstein, D. M. \& Bartley, D. A. (1971). Separation of free acids. $C_{2}-C_{5}$ in dilute aqueous solution column technology. Journal of Chromatographic Science 9, 673-681.

Trinder, P. (1969). Determination of glucose in blood using glucose oxidase with an alternative oxygen acceptor. Annals of Clinical Biochemistry 6, 24-27.

Zivin, J. A. \& Snarr, J. R. (1973). An automated colorimetric method for the measurement of 3-hydroxybutyrate concentration. Annals of Biochemistry 52, 456-461. 